\title{
Faktor-faktor yang mempengaruhi inflasi Provinsi-Provinsi di Sumatera
}

\section{Lailan Syafrina Hasibuan*; Rahma Nurjanah; Etik Umiyati}

\author{
Prodi Ekonomi Pembangunan Fakultas Ekonomi dan Bisnis, Universitas Jambi \\ *E-mail korespondensi: lailansyafrina40@gmail.com
}

\begin{abstract}
This study aims to: 1) analyze inflationary developments, road infrastructure, government spending, provincial minimum wage, and economic growth provincial in Sumatra; 2) analyze the influence of road infrastructure, government spending, provincial minimum wage, and economic growth provincial in Sumatra. This research uses a descriptive analysis method to determine the development of each research variable and quantitative methods using panel data regression approach random effect. Based on the descriptive analysis of inflationary development, road infrastructure stagnated, government spending, provincial minimum wage, and economic growth was increased every year. The regression of panel data with random effect approach variable of the provincial minimum wage has a positive and significant influence on the inflation of provincial in Sumatra. While road infrastructure, government spending, economic growth have no significant effect on provincial inflation in Sumatra.
\end{abstract}

\section{Keywords: Inflation, Government spending, Economic growth.}

\begin{abstract}
Abstrak
Tujuan penelitian ini adalah untuk: 1) menganalisis perkembangan inflasi, infrastruktur jalan, pengeluaran pemerintah, upah minimum provinsi dan pertumbuhan ekonomi Provinsi di Sumatera; 2) menganalisis pengaruh infrastruktur jalan, pengeluaran pemerintah, upah minimum provinsi dan pertumbuhan ekonomi Provinsi di Sumatera. Penelitian ini menggunakan metode analisis deskriptif untuk mengetahui perkembangan setiap variabel penelitian dan metode kuantitatif dengan menggunakan regresi data panel pendekatan random effect. Berdasarkan hasil analisis deskriptif perkembangan inflasi mengalami fluktuatif, infrastruktur jalan mengalami stagnan dan Pengeluaran pemerintah, upah minimum provinsi, pertumbuhan ekonomi mengalami peningkatan setiap tahunnya. Sedangkan hasil regresi data panel dengan pendekatan random effect variabel upah minimum provinsi berpengaruh positif dan signifikan terhadap inflasi provinsi di Sumatera. Sementara infrastruktur jalan, pengeluaran pemerintah, pertumbuhan ekonomi tidak berpengaruh signifikan terhadap inflasi Provinsi di Sumatera.
\end{abstract}

Kata kunci: Inflasi, Pengeluaran pemerintah, Pertumbuhan ekonomi.

\section{PENDAHULUAN}

Inflasi merupakan fenomena ekonomi yang sering terjadi pada perekonomian suatu negara. Gejala-gejala inflasi pada perekonomian ditandai dengan kenaikan harga secara umum dan berlangsung secara terus menerus (kontinu) ini akan mempengaruhi dan berdampak luas dalam berbagai bidang baik ekonomi, sosial maupun politik. Dalam sejarah perekonomian, Indonesia telah mengalami inflasi yang sangat tinggi, terutama pada tahun 1960-1990'an (tingkat inflasi semuanya diatas 100\%). Inflasi yang paling tinggi terjadi pada tahun 1966 yaitu sebesar 136\% disebabkan oleh defisit anggaran 
belanja pemerintah yang dibiayai dalam bentuk pencetakan uang. Namun inflasi pada tahun 1998-1999 merupakan salah satu inflasi yang tinggi di Indonesia yaitu sebesar $58 \%$ dan 20\% disebabkan oleh krisis moneter yang terjadi pada tahun 1997. Pada tahun 1998 adalah laju perekonomian terburuk di Indonesia yang saat itu dibawah pemerintahan Soeharto dengan inflasi sebesar $77,63 \%$ yang termasuk inflasi tinggi 30\%-100\% (BPS Indonesia).

Keynes menyatakan bahwa inflasi bukan hanya disebabkan oleh ekspansi moneter Bank Sentral saja melainkan juga melalui pengeluaran pemerintah. Menurut keynes, apabila pemerintah melakukan kebijakan fiskal yang ekspansif, yaitu dengan meningkatkan pengeluaran pemerintah, maka hal tersebut akan mendorong peningkatan harga atau akan memicu terjadi inflasi. Dengan kata lain, peningkatan pengeluaran Pemerintah melalui kebijakan fiskal ekspansif akan mendorong perekonomian sektor riil untuk tumbuh. Produktivitas perekonomian tersebut kemudian akan berdampak baik pada peningkatan permintaan akan barang input produksi maupun barang konsumsi seinggah menaikkan tingkat harga. (Boediono, 1994)

Mengacu pada teori pertumbuhan ekonomi regional tersebut, maka diprediksikan bahwa peningkatan dalam kualitas infrastruktur dalam distribusi produk akan menyebabkan penurunan biaya Transport dan penghematan waktu dalam perjalanan. Penghematan tersebut secara langsung akan mempengaruhi permintaan agregat, dampak dari peningkatan kualitas infrastruktur bisa menyebabkan kenaikan tingkat harga atau sebaliknya tergantung dari struktur perekonomian suatu negara atau wilayah. Peningkatan kualitas infrastruktur menyebabkan dua kondisi yang berbeda, yaitu akan mendorong peningkatan ekspor atau sebaliknya akan meningkatkan permintaan atas produk impor. Bila kemudian yang terjadi adalah peningkatan ekspor maka pengaruhnya terhadap harga cenderung menjadi negatif, namun jika yang terjadi sebaliknya dampaknya terhadap inflasi menjadi positif (Oosterhaven dan Elhorst, 2003).

Provinsi di Sumatera merupakan kawasan yang memiliki potensi yang cukup besar untuk berkembang dan maju melebihi kemajuan yang dicapai oleh Pulau Jawa, karena merupakan wilayah pengembangan pusat-pusat pertumbuhan yang akan menyerap investasi dan sumber daya untuk pertumbuhan ekonomi. Dalam meraih kemajuan ini diperlukan kerja sama yang erat antara provinsi-provinsi yang ada di Sumatera. Berdasarkan gambar 1 terlihat bahwa tingkat inflasi di Sumatera dan di Indonesia sama-sama tinggi. Berdasarkan data yang diperoleh dari BPS (2013) Sumatera merupakan wilayah yang tingkat inflasinya lebih tinggi dibandingkan Pulau Jawa yaitu sebesar 6,51\% untuk Sumatera dan 6,05\% untuk Pulau Jawa. Oleh sebab itu diperlukan kajian mendalam faktor yang mempengaruhi pergerakan inflasi Provinsi di Sumatera. Dengan demikian, berasarkan latar belakang yang diuraikan diatas, maka penulis merumuskan masalah yaitu: 1) Bagaimana pengaruh infrastruktur jalan, pengeluaran pemerintah, upah minimum provinsi, pertumbuhan ekonomi Provinsi di Sumatera.

\section{METODE}

Jenis data yang digunakan adalah data sekunder periode waktu 2011-2016 sebanyak 10 Provinsi. Metode analisis data dalam penelitian ini adalah metode deskriptif dan kuantitatif.

\section{Metode deskriptif}

Metode deskriptif merupakan metode yang digunakan untuk melihat perkembangan variabel dalam penelitian dengan menggunakan rumus sebagai berikuit:

$$
\Delta X_{n}=\frac{X_{n}-X_{n-1}}{X_{n-1}} X 100 \%
$$


Keterangan :

$\Delta X_{n} \quad=$ Persentase perkembangan pada tahun $\mathrm{n}$

$X_{n} \quad=$ Data tahun sekarang

$X_{n-1} \quad=$ Data tahun sebelumnya

\section{Metode kuantitatif}

Metode kuantitatif merupakan metode yang dilakukan untuk melihat pengaruh variabel bebas terhadap variabel terikat dengan menggunakan regresi data penel dengan 3 pendekatan sebagai berikut: 1).Pendekatan Commonded Effect, 2).Pendekatan Fixed Effect, 3).Pendekatan Random Effect

Dengan persamaan sebagai berikut:

$Y_{i t}=\alpha+\beta_{1} X_{1 i t}+\beta_{2} X_{2 i t}+\beta_{3} X_{3 i t}+\beta_{4} X_{4 i t}+u_{i t}$

Langkah-langkah penentuan model data panel sebagai berikut:

Uji Chow

$\mathrm{H}_{0}=$ Common effect

$\mathrm{H}_{\mathrm{I}}=$ Fixed effect

Uji Hausman

$\mathrm{H}_{0}=$ Random effect

$\mathrm{H}_{\mathrm{I}}=$ Fixed effect

\section{Uji LM}

$\mathrm{H}_{0}=$ Common effect

$\mathrm{H}_{\mathrm{I}}=$ Random effect

\section{HASIL DAN PEMBAHASAN}

\section{Perkembangan inflasi}

Inflasi yaitu kenaikan harga barang secara umum dan berlangsung secara terus menerus dan diikuti dengan menurunnya nilai mata uang dan daya beli masyarakat. Inflasi yang sering terjadi pada dasarnya terjadi karena kenaikan biaya produksi seperti BBM, Kenaikan Upah yang menyebabkan terjadinya pembengkakan biaya produksi yang pada akhirnya akan mendorong para produsen akan meningkatkan harga barang yang dijual di pasar. Dan jika proses ini berlangsung dalam waktu yang lama akan menyebabkan inflasi tinggi. Selain itu inflasi juga bisa disebabkan karena adanya peningkatan jumlah permintaan seperti pada saat lebaran, natal dan hari-hari besar lainnya hampir semua harga barang-barang secara umum mengalami kenaikan karena banyaknya permintaan dan jika hal ini berlangsung lama tentu saja akan menyebabkan inflasi.

Pada Tabel 1 menggambarkan perkembangan inflasi provinsi di Sumatera periode 2011-2016. Secara keseluruhan perkembangan inflasi tertinggi terjadi pada tahun 20132014 dimana Provinsi Sumatera Barat pada tahun 2014 sebesar 11.58 persen dengan rata-rata perkembangan sebesar 0.25 persen merupakan tingkat inflasi tertinggi di Sumatera. Sedangkan Jika dilihat dari rata-rata perkembangan inflasi provinsi-provinsi di Sumatera tertinggi adalah Provinsi Sumatera Utara sebesar 0.53 persen yang kedua Provinsi Jambi sebesar 0.36 persen dan diikuti oleh Provinsi Bangka Belitung sebesar 0.35 persen. Sedangkan rata-rata terendah adalah Provinsi Riau sebesar -0.31 persen dan Provinsi Lampung sebesar -0.30 persen. Tingginya tingkat inflasi Provinsi di Sumatera tahun 2013-2014 merupak imbas dari kebijakan pemerintah yang menaikkan harga 
bahan bakar minyak (BBM) yang mengakibatkan harga barang ikut meningkat sehingga memicu terjadinya inflasi.

Tabel 1. Perkembangan inflasi Provinsi di Sumatera tahun 2011-2016 (persen)

\begin{tabular}{|c|c|c|c|c|c|c|c|}
\hline \multirow{2}{*}{ Provinsi } & \multicolumn{6}{|c|}{ Tahun } & \multirow{2}{*}{$\begin{array}{c}\text { Rata-Rata } \\
(\%)\end{array}$} \\
\hline & 2011 & 2012 & 2013 & 2014 & 2015 & 2016 & \\
\hline NAD & 3.32 & 2.55 & 7.13 & 8.09 & 1.53 & 3.95 & 0.13 \\
\hline Sumatera Utara & 3.67 & 3.87 & 10.18 & 8.17 & 3.24 & 6.34 & 0.53 \\
\hline Sumatera Barat & 5.37 & 4.16 & 10.87 & 11.58 & 1.08 & 6.62 & 0.25 \\
\hline Jambi & 2.76 & 4.22 & 8.74 & 8.72 & 1.37 & 4.54 & 0.36 \\
\hline Riau & 5.57 & 3.32 & 8.79 & 8.65 & 2.65 & 4.04 & -0.31 \\
\hline Sumatera Selatan & 3.78 & 2.72 & 7.04 & 8.48 & 3.10 & 3.58 & -0.04 \\
\hline Lampung & 4.24 & 4.30 & 7.56 & 8.07 & 4.34 & 2.75 & -0.30 \\
\hline Bengkulu & 3.96 & 4.61 & 9.94 & 10.85 & 3.25 & 5.00 & 0.21 \\
\hline Kepulauan Riau & 6.39 & 2.38 & 8.24 & 7.59 & 4.40 & 7.59 & 0.24 \\
\hline Bangka Belitung & 5.00 & 6.57 & 8.71 & 9.06 & 3.27 & 6.75 & 0.35 \\
\hline
\end{tabular}

Sumber: Badan Pusat Statistik 2017(diolah)

\section{Perkembangan infrastruktur jalan}

Infrastruktur Jalan memiliki peranan penting dalam mendorong suatu perekonomian Negara atau wilayah. Tingginya kualitas infrastruktur jalan disuatu wilayah akan menciptakan kondisi yang berbeda, yakni akan mendorong peningkatan ekspor atau sebaliknya akan meningkatkan permintaan atas produk impor. Bila kemudian yang terjadi adalah peningkatan ekpspor maka pengaruhnya terhadap harga cenderung negatif, namun bila yang terjadi sebaliknya dampaknya terhadap inflasi menjadi positif

Secara keseluruhan Provinsi Sumatera Utara merupakan provinsi dengan total infrastruktur jalan tertinggi, hal itu dikarenakan selain wilayah yang luas dan kota yang maju pembangunan Infrastruktur jalan di Sumatera Utara merupakan proyek besar yang dilakukan pemerintah untuk menarik investor. Sedangkan Provinsi dengan total infrastruktur jalan terendah adalah Provinsi Bangka Belitung disebabkan karena wilayahnya yang tidak luas dan kurangnya modal pemerintah untuk mengusulkan jalan kabupaten menjadi jalan provinsi. Data lebih lengkapnya bisa dilihat pada tabel dibawah ini:

Tabel 2. Total kondisi infrastruktur jalan Provinsi di Sumatera tahun 2011-2016 (km)

\begin{tabular}{lcccccc}
\hline \multirow{2}{*}{ Provinsi } & \multicolumn{7}{c}{ Tahun } \\
\cline { 2 - 7 } & $\mathbf{2 0 1 1}$ & $\mathbf{2 0 1 2}$ & $\mathbf{2 0 1 3}$ & $\mathbf{2 0 1 4}$ & $\mathbf{2 0 1 5}$ & $\mathbf{2 0 1 6}$ \\
\hline NAD & 1.813 .33 & 1.570 .50 & 1.570 .51 & 1.803 .35 & 1.803 .35 & 1.781 .72 \\
Sumatera Utara & 3.048 .50 & 3.048 .50 & 3.048 .50 & 3.048 .50 & 3.048 .50 & 3.048 .50 \\
Sumatera Barat & 1.128 .31 & 1.153 .93 & 1.230 .53 & 1.230 .54 & 1.130 .53 & 1.130 .53 \\
Jambi & 2.417 .01 & 2.441 .41 & 2.441 .41 & 2.441 .41 & 2.447 .31 & 2.447 .83 \\
Riau & 3.033 .32 & 3.033 .32 & 3.033 .32 & 3.033 .32 & 3.033 .32 & 2.799 .90 \\
Sumatera Selatan & 1.620 .17 & 1.452 .18 & 1.462 .87 & 1.462 .87 & 1.471 .29 & 1.513 .65 \\
Lampung & 2.339 .73 & 1.525 .65 & 1.702 .81 & 1.702 .84 & 1.702 .81 & 1.702 .80 \\
Bengkulu & 1.222 .45 & 1.590 .52 & 1.507 .48 & 1.489 .29 & 1.562 .70 & 1.562 .70 \\
Kepulauan Riau & 679.49 & 679.49 & 679.49 & 679.49 & 679.49 & 679.49 \\
Bangka Belitung & 550.98 & 899.33 & 899.33 & 899.33 & 899.33 & 899.33 \\
\hline \multicolumn{1}{c}{ Sumatera } & $\mathbf{1 7 . 8 5 3 . 2 9}$ & $\mathbf{1 7 . 3 9 4 . 8 3}$ & $\mathbf{1 7 . 5 7 6 . 2 5}$ & $\mathbf{1 7 . 7 9 0 . 9 4}$ & $\mathbf{1 7 . 7 7 8 . 6 3}$ & $\mathbf{1 7 . 5 6 6 . 4 5}$ \\
\hline Sumber: Badanyyyyyyyyyyyyyy
\end{tabular}

Sumber: Badan Pusat Statistik 2016(diolah) 
Jika dilihat perkembangan infrastruktur provinsi-provinsi di Sumatera mengalami stagnan. Perkembangan rata-rata infrastruktur jalan tertinggi adalah Bangka Belitung sebesar 14 persen dan diikuti oleh Provinsi Sumatera Utara dengan rata-rata perkembangan sebesar 1.79 persen. Sedangkan rata-rata perkembangan terendah adalah Provinsi Lampung sebesar -3.8 persen. Dan untuk Sumatera sendiri mengalami fluktuasi selama periode 2011-2016. Peningkatan panjang jalan provinsi diakibatkan karena adanya perubahan status jalan kabupaten menjadi jalan provinsi, sementara penurunan panjang jalan provinsi diakibatkan karena perubahan status jalan provinsi menjadi jalan nasional.

Tabel 3. Perkembangan infrastruktur jalan Provinsi di Sumatera, 2011-2016 (persen)

\begin{tabular}{|c|c|c|c|c|c|c|c|c|}
\hline \multirow{2}{*}{ No } & \multirow{2}{*}{ Provinsi } & \multicolumn{6}{|c|}{ Tahun } & \multirow{2}{*}{$\begin{array}{c}\text { Rata-rata } \\
(\%)\end{array}$} \\
\hline & & 2011 & 2012 & 2013 & 2014 & 2015 & 2016 & \\
\hline 1 & NAD & 0.0 & -13.3 & 0.0 & 14.8 & 0.0 & -1.2 & 0.04 \\
\hline 2 & Sumatera Utara & 10.7 & 0.0 & 0.0 & 0.0 & 0.0 & 0.0 & 1.79 \\
\hline 3 & Sumatera Barat & -2.2 & 2.27 & 6.64 & 0.0 & -8.1 & 0.0 & -0.2 \\
\hline 4 & Jambi & 0.0 & 1.01 & 0.0 & 0.0 & 0.24 & 0.02 & 0.21 \\
\hline 5 & Riau & 0.0 & 0.0 & 0.0 & 0.0 & 0.0 & -7.7 & -1.2 \\
\hline 6 & Sumatera Selatan & 0.0 & -10.3 & 0.74 & 0.00 & 0.58 & 2.88 & -1.0 \\
\hline 7 & Lampung & 0.0 & -34.7 & 11.6 & 0.0 & 0.0 & 0.0 & -3.8 \\
\hline 8 & Bengkulu & -2.2 & 30.1 & -5.2 & -1.2 & 4.93 & 0.0 & 1.14 \\
\hline 9 & Kepulauan Riau & 0.0 & 0.0 & 0.0 & 0.0 & 0.0 & 0.0 & 0.0 \\
\hline 10 & Bangka Belitung & 21.1 & 63.2 & 0.0 & 0.0 & 0.0 & 0.0 & 14.0 \\
\hline & Sumatera & 0.14 & -2.57 & 1.04 & 1.22 & -0.1 & -1.2 & -0.2 \\
\hline
\end{tabular}

Sumber: Bps diolah 2016

\section{Perkembangan pengeluaran pemerintah}

Pengeluaran pemerintah merupakan salah satu penyebab terjadinya inflasi. Tingginya tingkat pengeluaran pemerintah akan mendorong meningkatnya jumlah uang beredar dan mengakibatkan terjadinya peningkatan harga atau akan memicu terjadi inflasi. Total pengeluaran provinsi-provinsi di Sumatera periode 2011-2016 mengalami peningkatan setiap tahunnya. Pada tahun 2011-2016 total pengeluaran tertinggi adalah Provinsi Aceh, kemudian diikuti oleh Provinsi Sumatera Utara, Riau, dan provinsi yang memiliki pengeluaran terendah adalah Provinsi Bangka Belitung dan Bengkulu. Dari keseluruhan pengeluaran tertinggi terjadi tahun 2016 sebesar Rp. 12.874.632 Juta merupakan pengeluaran Provinsi Aceh dan pengeluaran terendah sebesar Rp.1.009.215 Juta pada tahun 2011 oleh Provinsi Bengkulu.

Tabel 4. Total pengeluaran pemerintah Provinsi di Sumatera tahun 2011-2016 (juta)

\begin{tabular}{|c|c|c|c|c|c|c|}
\hline \multirow{2}{*}{ Provinsi } & \multicolumn{6}{|c|}{ Tahun } \\
\hline & 2011 & 2012 & 2013 & 2014 & 2015 & 2016 \\
\hline NAD & 7.374 .625 & 8.757 .320 & 11.220 .428 & 12.045 .848 & 12.149 .422 & 12.874 .632 \\
\hline Sumut & 4. & 7.633 .6 & 7.260 .468 & 7.808 .557 & 7.959 . & 9.950 .844 \\
\hline SumaBar & 2.328 .765 & 2.962 .291 & 3.113 .313 & 3.483 .673 & 4.022 .257 & 4.774 .204 \\
\hline Jambi & 1.750 .242 & 2.531 .598 & 3.010 .741 & 3.204 .633 & 3.425 .566 & 3.742 .023 \\
\hline Riau & 4.265 .130 & 6.670 .764 & 7.525 .283 & 5.602 .074 & 7.760 .972 & 10.972 .074 \\
\hline Sumsel & 3.806 .080 & 5.060 .923 & 5.678 .704 & 5.770 .733 & 5.190 .199 & 5.763 .643 \\
\hline Lampung & 2.566 .079 & 3.834 .736 & 3.884 .536 & 4.454 .187 & 4.781 .202 & 5.359 .403 \\
\hline Bengkulu & 1.009 .215 & 1.518 .453 & 1.727 .006 & 1.934 .722 & 2.282 .345 & 2.491 .703 \\
\hline Kepriau & 1.947 .593 & 2.249 .826 & 2.715 .832 & 3.312 .459 & 2.605 .394 & 3.056 .807 \\
\hline Babel & 1.176 .684 & 1.332 .039 & 3.884 .536 & 1.596 .087 & 1.869 .959 & 2.439 .183 \\
\hline
\end{tabular}

\begin{tabular}{lllllll} 
Sumatera & $\mathbf{3 0 . 8 3 5 . 8 9 0}$ & $\mathbf{4 2 . 5 5 1 . 5 8 4}$ & $\mathbf{5 0 . 0 2 0 . 8 4 7}$ & $\mathbf{4 9 . 2 1 2 . 9 7 3}$ & $\mathbf{5 2 . 0 4 6 . 4 8 3}$ & $\mathbf{6 1 . 4 2 4 . 5 1 6}$ \\
\hline
\end{tabular} Sumber : Badan Pusat Statistik (BPS) 2016(diolah) 
Berdasarkan Tabel 5 terlihat perkembangan pengeluaran pemerintah selama periode 2011-2016 mengalami fluktuasi. Dimana perkembangan pengeluaran pemerintah tertinggi terjadi pada tahun 2012 di Provinsi Riau sebesar 56.4 persen dengan rata-rata perkembangan pengeluaran pemerintah sebesar 9.8 persen dan perkembangan terendah terjadi pada Provinsi Bangka Belitung tahun 2014 sebesar -58.9 persen dengan rata-rata perkembangan pengeluaran tertinggi sebesar 38.3 persen

Tabel 5. Perkembangan pengeluaran pemerintah Provinsi di Sumatera tahun 2011-2016

\begin{tabular}{|c|c|c|c|c|c|c|c|c|}
\hline \multirow{2}{*}{ No } & \multirow{2}{*}{ Provinsi } & \multicolumn{6}{|c|}{ Tahun } & \multirow{2}{*}{$\begin{array}{c}\text { Rata-rata } \\
(\%)\end{array}$} \\
\hline & & 2011 & 2012 & 2013 & 2014 & 2015 & 2016 & \\
\hline 1 & NAD & -2.0 & 18.7 & 28.1 & 7.4 & 0.9 & 6.0 & 9.8 \\
\hline 2 & Sumatera Utara & 25.8 & 65.5 & -4.9 & 7.5 & 1.9 & 25.0 & 20.2 \\
\hline 3 & Sumatera Barat & 4.0 & 27.2 & 5.1 & 11.9 & 15.5 & 18.7 & 13.7 \\
\hline 4 & Jambi & 17.6 & 44.6 & 18.9 & 6.4 & 6.9 & 9.2 & 17.3 \\
\hline 5 & Riau & -0.1 & 56.4 & 12.8 & -25.6 & 38.5 & 41.4 & 20.6 \\
\hline 6 & Sumatera Selatan & 22.5 & 33.0 & 12.2 & 1.6 & -10.1 & 11.0 & 11.7 \\
\hline 7 & Lampung & 28.0 & 49.4 & 1.3 & 14.7 & 7.3 & 12.1 & 18.8 \\
\hline 8 & Bengkulu & 3.9 & 50.5 & 13.7 & 12.0 & 18.0 & 9.2 & 17.9 \\
\hline 9 & Kepulauan Riau & 13.0 & 15.5 & 20.7 & 22.0 & -21.3 & 17.3 & 11.2 \\
\hline \multirow[t]{2}{*}{10} & Bangka Belitung & 36.4 & 13.2 & 191.6 & -58.9 & 17.2 & 30.4 & 38.3 \\
\hline & Sumatera & 10.7 & 38.0 & 17.6 & -1.6 & 5.8 & 18.0 & 14.7 \\
\hline
\end{tabular}

Sumber:BPS diolah 2016

\section{Upah minimum provinsi (UMP)}

Upah minimum regional adalah upah yang ditetapkan secara bertahap agar agar setara dengan kebutuhan minimum. Upah minimum regional berlaku sampai tahun 1999 dan mulai tahun 2000 berlaku Upah Minimum Provinsi yang disebabkan dengan adanya otonomi daerah. Peraturan pemerintah mempunyai pengaruh terhadap standar tingkat upah, upah adalah harga yang harus dibayar perjam, hari, minggu dan perbulan. Upah sekaligus merupakan biaya produksi dipihak produsen dan merupakan sumber penghasilan bagi buruh.

Tabel 6. Upah Minimum Provinsi (UMP) Provinsi di Sumatera tahun 2011-2016 (rupiah)

\begin{tabular}{lcccccc}
\hline \multirow{2}{*}{ Provinsi } & \multicolumn{7}{c}{ Tahun } \\
\cline { 2 - 7 } & $\mathbf{2 0 1 1}$ & $\mathbf{2 0 1 2}$ & $\mathbf{2 0 1 3}$ & $\mathbf{2 0 1 4}$ & $\mathbf{2 0 1 5}$ & $\mathbf{2 0 1 6}$ \\
\hline NAD & 1.350 .000 & 1.400 .000 & 1.550 .000 & 1.750 .000 & 1.900 .000 & 2.118 .500 \\
Sumatera Utara & 1.035 .500 & 1.200 .000 & 1.375 .000 & 1.505 .850 & 1.625 .000 & 1.811 .875 \\
Sumatera Barat & 1.055 .000 & 1.150 .000 & 1.350 .000 & 1.490 .000 & 1.615 .000 & 1.800 .725 \\
Jambi & 1.028 .000 & 1.142 .500 & 1.300 .000 & 1.502 .300 & 1.710 .000 & 1.906 .650 \\
Riau & 1.120 .000 & 1.238 .000 & 1.400 .000 & 1.700 .000 & 1.878 .000 & 2.095 .000 \\
Sumsel & 1.048 .440 & 1.195 .220 & 1.630 .000 & 1.825 .000 & 1.974 .346 & 2.206 .000 \\
Lampung & 855.000 & 975.000 & 1.150 .000 & 1.399 .037 & 1.581 .000 & 1.763 .000 \\
Bengkulu & 815.000 & 930.000 & 1.200 .000 & 1.350 .000 & 1.500 .000 & 1.605 .000 \\
Kepriau & 975.000 & 1.015 .000 & 1.365 .087 & 1.665 .000 & 1.954 .000 & 2.178 .710 \\
Babel & 1.024 .000 & 1.110 .000 & 1.265 .000 & 1.640 .000 & 2.100 .000 & 2.341 .500 \\
\hline Sumatera & $\mathbf{1 0 . 3 0 5 . 9 4 0}$ & $\mathbf{1 1 . 3 5 5 . 7 2 0}$ & $\mathbf{1 3 . 5 8 5 . 0 8 7}$ & $\mathbf{1 5 . 8 2 7 . 1 8 7}$ & $\mathbf{1 7 . 8 3 7 . 3 4 6}$ & $\mathbf{1 9 . 8 2 6 . 9 6}$ \\
\hline Sumber: Badan Pusat Statistik,2016(diolah) & & & &
\end{tabular}

Secara umum Upah Minimum Provinsi di Sumatera terus mengalami peningkatan dari tahun ketahun. Tingkat upah tertinggi di Sumatera tahun 2011-2016 sebesar adalah Provinsi Bangka Belitung sebesar Rp.2.341.500 sedangkan tingkat upah terendah sebesar Rp.815.000 di Provinsi Bengkulu. Secara keseluruhan tingkat upah Sumatera 
mengalami peningkatan dari Rp.10.305.940-Rp.19.826.960. peningkatan upah setiap tahunnya sesuai dengan paket kebijakan ekonomi jilid 1V yang dikeluarkan pemerintah tentang pengupahan yang naik setiap tahunnya, tujuannya agar memberikan kepastian kepada buruh bahwa upah naik tiap tahun dan kepastian bagi dunia usaha dalam memprediksi upah pertahunnya. Berikut data tingkat upah pertahunnya di Sumatera.

Perkembangan upah minimum Provinsi di Sumatera periode 2011-2016. Perkembangan tingkat upah minimum tertinggi adalah Sumatera Selatan pada tahun 2013 yaitu sebesar 36.38 persen dari 14 persen pada tahun sebelumnya dengan rata-rata perkembangan sebesar 16.4 persen. Kemudian diikuti Provinsi Kepulauan Riau yaitu sebesar 34.4 persen dengan rata-rata perkembangan sebesar 17.8 persen. Sedangkan perkembangan upah minimum provinsi terendah adalah Provinsi Nangroe Aceh Darussalam yaitu sebesar 3.70 persen sangat jauh berbeda dengan perkembangan upah minimum provinsi lainnya pada tahun 2012 dengan rata-rata perkembangan sebesar 9.48 persen. Dan jika dilihat dari rata-rata perkembangan upah minimum provinsi tertinggi adalah Kepulauan Riau sebesar 17.8 persen dan terendah adalah Provinsi Nangroe Aceh Darussalam sebesar 9.84 persen. Secara keseluruhan perkembangan upah minimum provinsi tertinggi di Sumatera terjadi pada tahun 2013 sebesar 19.63 persen dengan rata-rata perkembangan sebesar 14 persen.

Tabel 7. Perkembangan tingkat UMP di Sumatera tahun 2011-2016

\begin{tabular}{|c|c|c|c|c|c|c|c|}
\hline \multirow{2}{*}{ Provinsi } & \multicolumn{6}{|c|}{ Tahun } & \multirow{2}{*}{$\begin{array}{c}\text { Rata-Rata } \\
(\%)\end{array}$} \\
\hline & 2011 & 2012 & 2013 & 2014 & 2015 & 2016 & \\
\hline NAD & 3.85 & 3.70 & 10.71 & 12.90 & 8.57 & 11.50 & 9.48 \\
\hline Sumatera Utara & 7.31 & 15.89 & 14.58 & 9.52 & 7.91 & 11.50 & 11.8 \\
\hline Sumatera Barat & 12.2 & 9.00 & 17.39 & 10.37 & 8.39 & 11.50 & 11.3 \\
\hline Jambi & 14.2 & 11.14 & 13.79 & 15.56 & 13.8 & 11.50 & 13.1 \\
\hline Riau & 10.2 & 10.54 & 13.09 & 21.43 & 10.5 & 11.55 & 13.4 \\
\hline Sumatera Selatan & 13.0 & 14.00 & 36.38 & 11.96 & 8.18 & 11.73 & 16.4 \\
\hline Lampung & 11.4 & 14.04 & 17.95 & 21.66 & 13.0 & 11.51 & 15.6 \\
\hline Bengkulu & 4.49 & 14.11 & 29.03 & 12.50 & 11.1 & 7.00 & 14.7 \\
\hline Kepulauan Riau & 5.41 & 4.10 & 34.4 & 21.9 & 17.4 & 11.50 & 17.8 \\
\hline Bangka Belitung & 12.5 & 8.40 & 13.96 & 29.64 & 28.0 & 11.50 & 18.3 \\
\hline Sumatera & 9.27 & 10.19 & 19.63 & 16.50 & 12.7 & 11.15 & 14.0 \\
\hline
\end{tabular}

Sumber: Badan Pusat Statistik, 2016(diolah)

\section{Pertumbuhan ekonomi}

Pertumbuhan ekonomi merupakan salah satu indikator untuk mengukur suatu keberhasilan ekonomi suatu daerah. Pertumbuhan ekonomi menggambarkan suatu dampak nyata dari kebijakan pembangunan yang akan dilaksanakan suatu negara atau daerah khususnya dibidang ekonomi. Perkembangan suatu daerah dapat dinilai dari peningkatan produk domestik regional bruto dari tahun ketahun yang dinyatakan dalam persen. Tinggi rendahnya laju pertumbuhan ekonomi akan berdampak terhadap laju inflasi. Laju pertumbuhan ekonomi Provinsi-Provinsi di Sumatera selama periode 20112016 menunjukkan cenderung menurun.

Berdasarkan Tabel 8. dapat dijelaskan bahwa rata-rata pertumbuhan ekonomi tahun 2011-2016 di Sumatera mengalami penurunan dari tahun ke tahun. Rata-rata pertumbuhan ekonomi tertinggi terjadi pada tahun 2011 sebesar 6.33 persen dan laju pertumbuhan terendah terjadi pada tahun 2015 sebesar 3.92 persen. Dari 10 Provinsi yang ada di Sumatera laju pertumbuhan ekonomi tertinggi yaitu Provinsi Jambi sebesar 7.86 persen pada tahun 2011 yang disebabkan karena besarnya pengaruh lapangan usaha dalam bidang pertanian, kehutanan dan perikanan yang meningkat dari tahun sebelumnya . Sedangkan pertumbuhan ekonomi terendah yaitu Provinsi Nangroe Aceh 
Darussalam yaitu sebesar $-0,72$ pada tahun 2015 rendahnya pertumbuhan ekonomi di Nangroe Aceh Darussalam disebabkan karena perekonomian di NAD memburuk stelah terjadinya tsunami pada tahun 2004 yang berdampak pada jangka panjang. Dan jika dilihat secara rata-rata Provinsi yang tertinggi yaitu Provinsi Kepulauan Riau sebesar 6.57 persen dan diikuti oleh Provinsi Jambi sebesar 6.28 persen. Dan rata-rata terendah adalah Provinsi Nangroe Aceh Darussalam sebesar 2.31 persen.

Tabel 8. Perkembangan pertumbuhan ekonomi provinsi di Sumatera, 2011-2016 (\%)

\begin{tabular}{|c|c|c|c|c|c|c|c|c|}
\hline \multirow{2}{*}{ No } & \multirow{2}{*}{ Provinsi } & \multicolumn{6}{|c|}{ Tahun } & \multirow{2}{*}{$\begin{array}{c}\text { Rata-rata } \\
(\%)\end{array}$} \\
\hline & & 2011 & 2012 & 2013 & 2014 & 2015 & 2016 & \\
\hline 1 & NAD & 3.28 & 3.85 & 2.61 & 1.55 & -0.72 & 3.30 & 2.31 \\
\hline 2 & Sumatera Utara & 6.66 & 6.45 & 6.07 & 5.23 & 5.10 & 5.17 & 5.78 \\
\hline 3 & Sumatera Barat & 6.34 & 6.31 & 6.08 & 5.86 & 5.54 & 5.26 & 5.90 \\
\hline 4 & Jambi & 7.86 & 7.03 & 6.84 & 7.35 & 4.21 & 4.37 & 6.28 \\
\hline 5 & Riau & 5.57 & 3.76 & 2.48 & 2.70 & 0.23 & 2.23 & 2.83 \\
\hline 6 & Sumatera Selatan & 6.36 & 6.83 & 5.31 & 4.70 & 4.50 & 5.03 & 5.46 \\
\hline 7 & Lampung & 6.56 & 6.44 & 5.77 & 5.08 & 5.14 & 5.15 & 5.69 \\
\hline 8 & Bengkulu & 6.85 & 6.83 & 6.07 & 5.48 & 5.13 & 5.30 & 5.94 \\
\hline 9 & Kepulauan Riau & 6.96 & 7.63 & 7.21 & 6.62 & 5.98 & 5.04 & 6.57 \\
\hline 10 & Bangka Belitung & 6.90 & 5.50 & 5.20 & 4.66 & 4.08 & 4.12 & 5.08 \\
\hline & Sumatera & 6.33 & 6.06 & 5.36 & 4.92 & 3.92 & 4.50 & 5.18 \\
\hline
\end{tabular}

Sumber: Badan Pusat Statistik (BPS) 2016

\section{Analisis regresi data panel \\ Common effect}

Hasil dari pengolahan data dengan menggunakan Common Effect sebagai berikut:

$$
\begin{aligned}
& \text { INFit }=2.47+0.036 \mathrm{Git}+0.030 \mathrm{INJit}+0.152 \mathrm{UMPit}-0.112 \mathrm{PDRBit}
\end{aligned}
$$

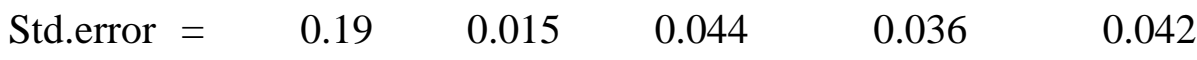

$$
\begin{aligned}
& \begin{array}{llllll}
\mathrm{t} \text {-stat } & =12.52 & -2.32 & 0.69 & 4.16 & -2.65
\end{array} \\
& \text { Adjs R2 }=0.44 \\
& \mathrm{~F} \quad=12.8
\end{aligned}
$$

\section{Fixed effect}

Hasil dari pengolahan data dengan pendekatan Fixed Effect sebagai berikut:

$$
\begin{aligned}
& \text { INFit }=1.7864+0.078 \text { Git }-0.038 \text { INJit + 0.118UMPit + 0.012PDRBit } \\
& \begin{array}{lllll}
\text { Std.error }=0.57 & 0.181 & 0.037 & 0.042 & 0.047
\end{array} \\
& \begin{array}{llllll}
\text { t-stat } & =3.1 & 0.43 & -1.01 & 2.80 & 0.25
\end{array} \\
& \text { Adjs R2 }=0.74 \\
& \mathrm{~F} \quad=13.8
\end{aligned}
$$

Tabel 9. Nilai intersep fixed effect Provinsi di Sumatera

\begin{tabular}{llc}
\hline No & \multicolumn{1}{c}{ Provinsi } & Nilai Intersep \\
\hline 1 & NAD & 0.836496 \\
2 & Sumatera Utara & 0.846033 \\
3 & Sumatera Barat & 0.151426 \\
4 & Jambi & -0.021527 \\
5 & Riau & 0.043459 \\
6 & Sumatera Selatan & 0.521576 \\
7 & Lampung & 0.347396 \\
8 & Bengkulu & -0.473556 \\
9 & Kepulauan Riau & -0.811312 \\
10 & Bangka Blitung & -1.439994 \\
\hline
\end{tabular}

Sumber: Data diolah, 2017 


\section{Random effect}

Hasil dari pengolahan data dengan pendekatan Random Effect sebagai berikut: INFit $=2.21+0.048$ Git -0.025 INJit + 0.122UMPit -0.022 PDRBit

$\begin{array}{llllll}\text { Std.Error } & =0.24 & 0.031 & 0.036 & 0.038 & 0.041 \\ \text { t-stat } & =8.94 & -1.53 & -0.71 & 3.14 & -0.54 \\ \text { Adjs R2 } & =0.54 & & & & \\ \text { F } & =4.97 & & & & \end{array}$

Tabel 10. Nilai intersep random effect Provinsi di Sumatera

\begin{tabular}{llc}
\hline No & \multicolumn{1}{c}{ Provinsi } & Nilai Intersep \\
\hline 1 & NAD & 0.487100 \\
2 & Sumatera Utara & 0.546435 \\
3 & Sumatera Barat & -0.189905 \\
4 & Jambi & -0.259855 \\
5 & Riau & -0.184760 \\
6 & Sumatera Selatan & 0.175964 \\
7 & Lampung & 0.085589 \\
8 & Bengkulu & -0.612646 \\
9 & Kepulauan Riau & 0.188193 \\
10 & Bangka Blitung & -0.236114 \\
\hline
\end{tabular}

Sumber: Data diolah, 2017

\section{Pemilihan model estimasi}

Berdasarkan hasil regresi data panel dengan pendekatan common effect, fixed effect dan random effect maka langkah berikutnya adalah pemilihan model terbaik yang dilakukan dengan Uji Chow, Uji Hausman Dan Uji LM.

\section{Uji Chow}

Uji Chow bertujuan untuk mengetahui apakah sebaiknya model menggunakan common effect ataukah fixed effect. Hipotesis dalam Uji ini adalah sebagai berikut:

$\mathrm{H}_{0}=$ Common effect

$\mathrm{H}_{\mathrm{I}}=$ Fixed effect

Apabila nilai dari probabilitas Chi-Square kurang dari 5\% maka $\mathrm{H}_{0}$ ditolak. Sehingga model yang terbaik adalah fixed effect.

Tabel 11. Hasil analisis uji chow

\begin{tabular}{lcc}
\hline Effect Test & d.f. & Probabilitas \\
\hline Cross-sectionF & $(9,46)$ & 0.0000 \\
Cross-section Chi-square & 9 & 0.0000 \\
\hline
\end{tabular}

Sumber: Data diolah, 2017

Berdasarkan tabel 2 Diketahui probabilitas Chi-square sebesar 0.0000. Nilai probabilitas $0.0000<5 \%$ seinggah $\mathrm{H}_{0}$ ditolak maka model yang sebaiknya digunakan adalah model Fixed Effect.

\section{Uji hausman}

Uji Hausman bertujuan untuk mengetahui apakah model Random Effect lebih baik digunakan dari pada model Fixed Effect. Hipotesis yang digunakan dalam Uji Hausman adalah sebagai berikut: 
$\mathrm{H}_{0}=$ Random effect

$\mathrm{H}_{\mathrm{I}}=$ Fixed effect

Apabila nilai probabilitas chi-square lebih dari 5\%, maka sebaiknya model menggunakan Random Effect.

Tabel 12. Hasil analisis uji hausman

\begin{tabular}{lccc}
\multicolumn{1}{c}{ Test Summary } & Chi-Sq. Statistic & Chi-Sq.d.f. & Probabilitas \\
\hline Cross-section random & 3.930762 & 4 & 0.4155 \\
\hline Sumber: Data diolah, 2017 & & &
\end{tabular}

Berdasarkan tabel 12 Diketahui nilai probabilitas sebesar 0.4155 dan nilai 0.4155 $<5 \%$, maka model yang sebaiknya digunakan dalam penelitian ini adalah model Random Effect.

\section{Uji lagrange multiplier (LM)}

Uji LM bertujuan untuk mengetahui apakah model Random Effect lebih baik digunakan dari pada model Common Effect. Hipotesis yang digunakan dalam penelitian ini adalah sebagai berikut:

$\mathrm{H}_{0}=$ Common effect

$\mathrm{H}_{\mathrm{I}}=$ Random effect

Apabila nilai probabilitas Breusch-Pagan $<5 \%$ maka $\mathrm{H}_{0}$ ditolak, maka sebaiknya model menggunakan Random Effect.

Tabel 13. Hasil analisis uji LM

\begin{tabular}{cccc}
\hline $\begin{array}{c}\text { Null (no rand effect) } \\
\text { Alternative }\end{array}$ & $\begin{array}{c}\text { Cross-section } \\
\text { One-sided }\end{array}$ & $\begin{array}{c}\text { Period } \\
\text { One-side }\end{array}$ & \multirow{2}{*}{ Both } \\
\hline Breusch-Pagan & 2.623303 & 147.4153 & 150.0385 \\
& $(0.1053)$ & $(0.0000)$ & $(0.0000)$ \\
\hline
\end{tabular}

Sumber: Data diolah, 2017

Berdasarkan Tabel 13 diketahui nilai probabilitas Breusch-Pagan $0.0000<5 \%$ maka $\mathrm{H}_{0}$ ditolak sehingga model yang sebaiknya digunakan dalam penelitian ini adalah Random effect.

\section{Uji hipotesis}

Setelah memilih model mana yang terbaik dilanjutkan dengan uji hipotesis. Uji hipotesis dilakukan dengan uji signifikan statistik secara uji $\mathrm{F}$ dan parsial atau uji-t.

\section{Uji simultan (Uji F)}

Berdasarkan hasil analisis, diperoleh nilai F-hitung sebesar 4.9748 dengan nilai probabilitasnya 0.001703 dalam taraf signifikansi 5\% Maka dapat disimpulkan bahwa pengeluaran pemerintah, infrastruktur jalan, upah minimum provinsi dan pertumbuhan ekonomi secara bersama-sama berpengaruh signifikan terhadap inflasi Provinsi di Sumatera.

\section{Uji parsial (Uji t)}

Dari hasil regresi Random Effect didapat nilai t-hitung Pengeluaran Pemerintah 1.53 dengan nilai probabilitas 0.0017 dalam taraf signifikan $a=5 \%$. Ditarik kesimpulan pengeluaran pemerintah berpengaruh positif dan signifikan terhadap inflasi Provinsi di 
Sumatera, Infrastruktur Jalan didapat nilai t-hitung -0.713 dengan nilai probabilitas 0.47 signifikan $\mathrm{a}=5 \%$. Ditarik kesimpulan infrastruktur jalan tidak berpengaruh signifikan terhadap inflasi Provinsi di Sumatera.Upah Minimum Provinsi didapat nilai t-hitung 3.145 dengan nilai probabilitas 0.002 signifikan $\mathrm{a}=5 \%$. Artinya Upah Minimum Provinsi berpengaruh positif dan signifikan terhadap inflasi Provinsi di Sumatera. Maka ditarik kesimpulan semakin besar tingkat upah minimum provinsi maka inflasi akan meningkat. Pertumbuhan Ekonomi didapat nilai t-hitung -0.540 dengan nilai probabilitas 0.5911 signifikan $\mathrm{a}=5 \%$ artinya pertumbuhan ekonomi tidak bepengaruh signifikan terhadap inflasi Provinsi di Sumatera

\section{Koefisien determinasi}

Berdasarkan hasil estimasi diperoleh nilai Adjusted R-square sebesar 0.52 artinya selama periode penelitian pengeluaran pemerintah, infrastruktur jalan, upah minimum provinsi dan pertumbuhan ekonomi mampu mempengaruhi inflasi sebesar 52 persen sedangkan 48 persen dipengaruhi oleh variabel lain (Cateris paribus).

Model Random Effect memiliki nilai intersep yang berbeda-beda tiap Provinsi lihat tabel 13 Keadaan tersebut dapat dijelaskan bahwa pengeluaran pemerintah, infrastruktur jalan, upah minimum provinsi dan pertumbuhan ekonomi memiliki tingkat pengaruh berbeda terhadap inflasi tiap-tiap Provinsi di Sumatera maupun tiap tahunnya. Intersep Random Effect tersebut menunjukkan bahwa bila terdapat perubahan 1 persen dari pengeluaran pemerintah, infrastruktur jalan, upah minimum provinsi dan pertumbuhan ekonomi tiap Provinsi di Sumatera.

\section{Nilai intersep Provinsi Aceh (0.487100+2.217534)}

Jika ada perubahan dari pengeluaran pemerintah, infrastruktur jalan, upah minimum provinsi dan pertumbuhan ekonomi baik antar Provinsi maupun antar waktu, maka Provinsi Aceh mendapatkan pengaruh individu terhadap inflasi sebesar 2,704634.

\section{Nilai intersep Sumatera Utara $(0.546435+2.217534)$}

Jika ada perubahan dari pengeluaran pemerintah, infrastruktur jalan, upah minimum provinsi dan pertumbuhan ekonomi baik antar Provinsi maupun antar waktu, maka Provinsi Sumatera Utara mendapatkan pengaruh individu terhadap inflasi sebesar 2,763969 .

\section{Nilai intersep Sumatera Barat (-0.189905+2.217534)}

Jika ada perubahan dari pengeluaran pemerintah, infrastruktur jalan, upah minimum provinsi dan pertumbuhan ekonomi baik antar Provinsi maupun antar waktu, maka Provinsi Sumatera Barat mendapatkan pengaruh individu terhadap inflasi sebesar 2,027629 .

\section{Nilai intersep Provinsi Jambi (-0.259855+2.217534)}

Jika ada perubahan dari pengeluaran pemerintah, infrastruktur jalan, upah minimum provinsi dan pertumbuhan ekonomi baik antar Provinsi maupun antar waktu, maka Provinsi Jambi mendapatkan pengaruh individu terhadap inflasi sebesar 1,957679.

\section{Nilai intersep Provinsi Riau (-0.184760+2.217534)}

Jika ada perubahan dari pengeluaran pemerintah, infrastruktur jalan, upah minimum provinsi dan pertumbuhan ekonomi baik antar Provinsi maupun antar waktu, maka Provinsi Riau mendapatkan pengaruh individu terhadap inflasi sebesar 2,032774. 


\section{Nilai intersep Sumatera Selatan $(0.175964+2.217534)$}

Jika ada perubahan dari pengeluaran pemerintah, infrastruktur jalan, upah minimum provinsi dan pertumbuhan ekonomi baik antar Provinsi maupun antar waktu, maka Provinsi Sumatera Selatan mendapatkan pengaruh individu terhadap inflasi sebesar 2,393498.

\section{Nilai intersep Provinsi Lampung (0.085589+2.217534)}

Jika ada perubahan dari pengeluaran pemerintah, infrastruktur jalan, upah minimum provinsi dan pertumbuhan ekonomi baik antar Provinsi maupun antar waktu, maka Provinsi Lampung mendapatkan pengaruh individu terhadap inflasi sebesar 2,303123 .

\section{Nilai intersep Provinsi Bengkulu (-0.612646+2.217534)}

Jika ada perubahan dari pengeluaran pemerintah, infrastruktur jalan, upah minimum provinsi dan pertumbuhan ekonomi baik antar Provinsi maupun antar waktu, maka Provinsi Bengkulu mendapatkan pengaruh individu terhadap inflasi sebesar 1,604888 .

\section{Nilai intersep Provinsi Kepulauan Riau (0.1881193+2.217534)}

Jika ada perubahan dari pengeluaran pemerintah, infrastruktur jalan, upah minimum provinsi dan pertumbuhan ekonomi baik antar Provinsi maupun antar waktu, maka Provinsi Kepulauan Riau mendapatkan pengaruh individu terhadap inflasi sebesar 2,405653 .

\section{Nilai intersep Kepulauan Bangka Belitung (-0.236114+2.217534)}

Jika ada perubahan dari pengeluaran pemerintah, infrastruktur jalan, upah minimum provinsi dan pertumbuhan ekonomi baik antar Provinsi maupun antar waktu, maka Provinsi Kepulauan Bangka Belitung mendapatkan pengaruh individu terhadap inflasi sebesar 1,98142 .

\section{Implikasi hasil penelitian}

Untuk mengendalikan inflasi dapat dilakukan dengan menggunakan kebijakan moneter, kebijakan fiskal dan kebijakan non moneter. Sasaran kebijakan moneter dicapai melalui pengaturan jumlah uang beredar, sasaran kebijakan fiskal menyangkut pengaturan tentang pengeluaran pemerintah serta perpajakan dan sasaran kebijakan non moneter menyangkut penentuan tingkat upah dan harga.

Dari hasil estimasi pengeluaran pemerintah berpengaruh positif terhadap inflasi Provinsi di Sumatera, hal ini sesuai dengan peningkatan pengeluaran pemerintah Provinsi di Sumatera setiap tahunnya. Peningkatan pengeluaran pemerintah akan mendorong peningkatan harga atau akan memicu terjadinya inflasi. Pemerintah daerah sebaiknya mengendalikan pengeluarannya dengan peningkatan efisiensi alokasi anggaran dan memberikan bobot yang lebih besar kepada belanja modal bila dibandingkan dengan belanja barang.

Dari hasil estimasi Upah Minimum Provinsi UMP) berpengaruh positif dan signifikan terhadap pergerakan inflasi Provinsi di Sumatera. Peningkatan upah minimum provinsi (UMP) Provinsi di Sumatera meningkat setiap tahunnya sesuai juga dengan keputusan kementerian ketenagakerjaan (Kemenaker) masing-masing daerah. 
Peningkatan tersebut seharusnya pemerintah menetapkan besaran tingkat upah sesuai dengan besaran inflasi. Tidak hanya itu pemerintah harus melakukan pengawasan dan mengevaluasi upah agar tetap stabil sesuai dengan tingkat inflasi masing-masing Provinsi agar tidak memicu terjadinya inflasi.

\section{KESIMPULAN DAN SARAN}

\section{Kesimpulan}

Perkembangan inflasi Provinsi di Sumatera periode 2011-2016 tertinggi adalah Provinsi Sumatera Barat. Rata-rata perkembangan Infrastruktur Jalan di Sumatera tertinggi Bangka Belitung dan terendah adalah Lampung. Perkembangan pengeluaran pemerintah rata-rata perkembangan tertinggi adalah Riau dan terendah adalah Bangka Belitung. Perkembangan Tingkat Upah Minimum Provinsi tertinggi yaitu Sumatera Selatan dan terendah Nangroe Aceh Darussalam. Laju Pertumbuhan Ekonomi tertinggi adalah Kepulauan Riau dan terendah adalah Nangroe Aceh Darussalam.

Hasil analisis regresi berganda data panel dengan pendekatan Random Effect diperoleh variabel yang berpengaruh signifikan adalah variabel Pengeluaran Pemerintah (G) dan Upah Minimum Provinsi (UMP). Secara bersama-sama (Uji F-statistik) variabel bebas Infrastruktur Jalan (INJ), Pengeluaran Pemerintah (G), Upah Minimum Provinsi (UMP) dan Pertumbuhan Ekonomi (PDRB) berpengaruh signifikan terhadap variabel tidak bebas dalam hal ini Inflasi (INF) Provinsi di Sumatera.

\section{Saran}

Upah Minimum Provinsi (UMP) dan Pengeluaran pemerintah (G) merupakan salah satu variabel yang dapat memicu terjadinya inflasi di Sumatera, sehingga dalam hal ini Pemerintah diharapkan dapat memperhatikan dan mempertimbangkan besarnya penyesuaian tingkat pengeluaran pemerintah dan upah minimum provinsi agar.

\section{DAFTAR PUSTAKA}

Aditya, R. (2012). Faktor-faktor yang mempengaruhi inflasi di Pulau Jawa: Analisis Data Panel. Institut Pertanian Bogor: Bogor.

Atmadja, A.S. (1999). Inflasi di Indonesia: sumber-sumber penyebab dan cara pengendaliannya. Jurnal Akuntansi dan Keuangan. 1 (1) : 54-67.

Badan Pusat Statistik. (2009-2017). Data inflasi, Infrastruktur, dan pengeluaran pemerintah. Provinsi Dalam Angka diakses dalam http://bps.go.id, Tanggal 22 Agustus 2021, Pukul 20.00 WIB

Gujarati, Damodar N dan Dawn C porter.(2012). Dasar-dasar ekonometrika.Jakarta: Salemba Empat.

Gujarati, Damodar.(2003). Econometric, Erlangga: Jakarta

H Harlik, A Amir, H Hardiani. (2013).Faktor-faktor yang mempengaruhi kemiskinan dan pengangguran di Kota Jambi, Jurnal Perspektif Pembiayaan dan Pembangunan Daerah 1 (2), 109-120

Hamza, Z. (2006). Pengaruh jumlah uang beredar, pengeluaran pemerintah, dan nilai tukar terhadap inflasi di Indonesia. IPB. Bogor.

Hoover, Giarratani.(1989).An introduction to regional economic. Utenti.dea.univp. 
Juanda dan Junaidi.(2012). Ekonometrika deret waktu teori dan aplikasi, PT Penerbit IPB Press: Bogor.

Lavianty, Elmi.(2016). Pengaruh PDRB, investasi, upah dan inflasi terhadap penyerapan tenaga kerja di Pulau Jawa tahun 2008-2013. upb, bandung.

Lestari, N.(2003). Analisis faktor-faktor yang mempengaruhi inflasi pada perekonomian regional di Indonesia (Thesis). Universitas Indonesia: Depok.

Mishkin, (2009). Ekonomi uang, Perbankan, dan Pasar Keuangan. Salemba: Jakarta Nopirin, (2014). Ekonomi moneter. BPFE: Yogyakarta.

R Rosmeli, N Nurhayani. (2014). Studi komperatif ketimpangan wilayah antara Kawasan Barat Indonesia dan Kawasan Timur Indonesia. Jurnal Manajemen Terapan dan Keuangan 3 (1), 456-463

Suardi, Endang.(2012). Harga bahan bakar minyak dan inflasi. Artikel Ilmiah.

Subekti, A.(2011). Dinamika inflasi di Indonesia pada tataran provinsi (Thesis). IPB: Bogor.

Sukirno, Sadono.(2010). Makro ekonomi. PT. Raja Grafindo Persada: Jakarta 